\section{Fruit Morphology and Fruit Strength in a Seedling Population of Red Raspberry}

\section{JoAnn Robbins ${ }^{1}$ and Patrick P. Moore ${ }^{2}$ \\ Washington State University Puyallup Research and Extension Center, Puyallup, WA 98371}

Additional index words. compression, firmness, Rubus idaeus, fruit quality, path analysis

Abstract. Weight and morphological characteristics of red raspberry (Rubus idaeus L.) fruit, including drupelets (height, diameter, number), receptacle cavities (depth, diameter), and pits (individual weight), were measured on 78 seedlings from the cross 'Chief' $\times$ 'Chilliwack'. Fruit strength, as measured by compression, correlated with fruit weight, drupelet number, receptacle cavity depth, and individual pit weight. Fruit weight was positively correlated with all morphological characteristics. Individual pit weight, drupelet height, and drupelet number provided the largest component contributions to fruit strength as measured by path analysis.
In raspberry, fruit strength is important in the maintenance of fresh-market (Sjulin and Robbins, 1984) and canning (Reeve et al., 1965) quality. There are significant differences in fruit strength between genotypes (Barritt et al., 1980) and many variations in fruit morphological characteristics (Robbins and Sjulin, 1989). As part of our work to develop firm-fruited raspberry cultivars eslife, we have investigated the relationship of fruit morphological characteristics to fruit strength (Robbins and Moore, 1990; Robbins and Sjulin, 1989; Robbins et al., 1988). Previous work, where fruit characteristics of 10 cultivars were subjected to path analysis (Li, 1975), showed that drupelet height and number, receptacle cavity depth and diameter, and individual pit weight provided the largest component contributions to fruit strength as measured by compression (force required to close the fruit opening) (Robbins and Sjulin, 1989). All components, except individual pit weight, influenced fruit strength by increasing fruit weight, and heavier fruit were stronger. Pit weight influenced fruit strength directly.

Further studies investigated the relationship of fruit strength, fruit weight, and morphological characteristics within the single genotype 'Meeker' (Robbins and Moore, 1990). In 'Meeker', heavier fruit were stronger up to an optimum fruit weight, beyond which fruit strength decreased. Path analysis showed that drupelet number, receptacle cavity depth, and individual pit

Received for publication 14 June 1990. H/LA Paper no. 90-08. Washington State Univ., College of Agriculture and Home Economics, Pullman. Project no. 0640. Partially supported by a grant from the Washington Red Raspberry Commission. The cost of publishing this paper was defrayed in part by the payment of page charges. Under postal regulations, this paper therefore must be hereby marked advertisement solely to indicate this fact. 'Horticulture Research Specialist.

${ }^{2}$ Assistant Horticulturist. pecially suited for a long fresh-market shelf weight made strong, direct contributions to fruit strength. Drupelet height varied little within the single genotype, and its total path coefficient to fruit strength was small. Receptacle cavity diameter contributed largely to fruit weight, thereby detracting from fruit strength, and contributed little to fruit strength directly.

Our first study (Robbins and Sjulin, 1989) primarily used cultivars of large size and high fruit strength. By collecting data on a population including large, soft fruit and small, firm fruit, a clearer relationship among fruit strength, berry weight, and morphological characteristics might be found. We, therefore, report on our study of the relationships among fruit strength, berry weight, and morphological characteristics in a diverse, unselected seedling population.
Seventy-eight seedlings were used from the cross of 'Chief' $\times$ 'Chilliwack'. 'Chief' is a cultivar with small (1984 seasonal mean weight $\approx 1.7 \mathrm{~g}$ ), relatively soft (1984 seasonal mean fruit strength $\approx 0.60 \mathrm{~N}$ ) fruit that are rounded (Robbins and Sjulin, unpublished data). 'Chilliwack' is a cultivar with large (1989 seasonal mean weight $\approx 3.6 \mathrm{~g}$ ), firm ( 1989 seasonal mean fruit strength $\approx 2.0$ $\mathrm{N})$ fruit that are long (unpublished data). Samples were randomly chosen from a population of 101 seedlings with the expectation of obtaining a sample with a wide range of and various combinations of fruit weights, strength; drupelet height, diameter, and number; receptacle cavity depth and diameter; and individual pit weight were measured, as described by Robbins and Moore (1990), on five fruit from each seedling. Fruit were harvested at the red-ripe stage (Sjulin and Robbins, 1987) and selected for uniform size typical of the seedling at time of harvest. The mean of the five fruit measurements were used for data analysis.

The mean, standard deviation, coefficient of variation, and range of fruit measurements were calculated over all seedlings (Table 1). Correlations of fruit morphological measurements with fruit weight and fruit strength were determined (Table 2). All measured morphological characteristics were positively correlated to fruit weight, including fruit strength (Table 2). Thus, larger morphological characteristics were associated with greater fruit weight, and the heavier berries were firmer. Other than fruit weight, only drupelet number, receptacle cavity depth, and individual pit weight were correlated to fruit strength.

Using path analyses (Li, 1975) and the diagrammatic representation proposed in previous work (Robbins and Moore, 1990; Robbins and Sjulin, 1989), estimations of strengths, and shapes. Fruit weight and

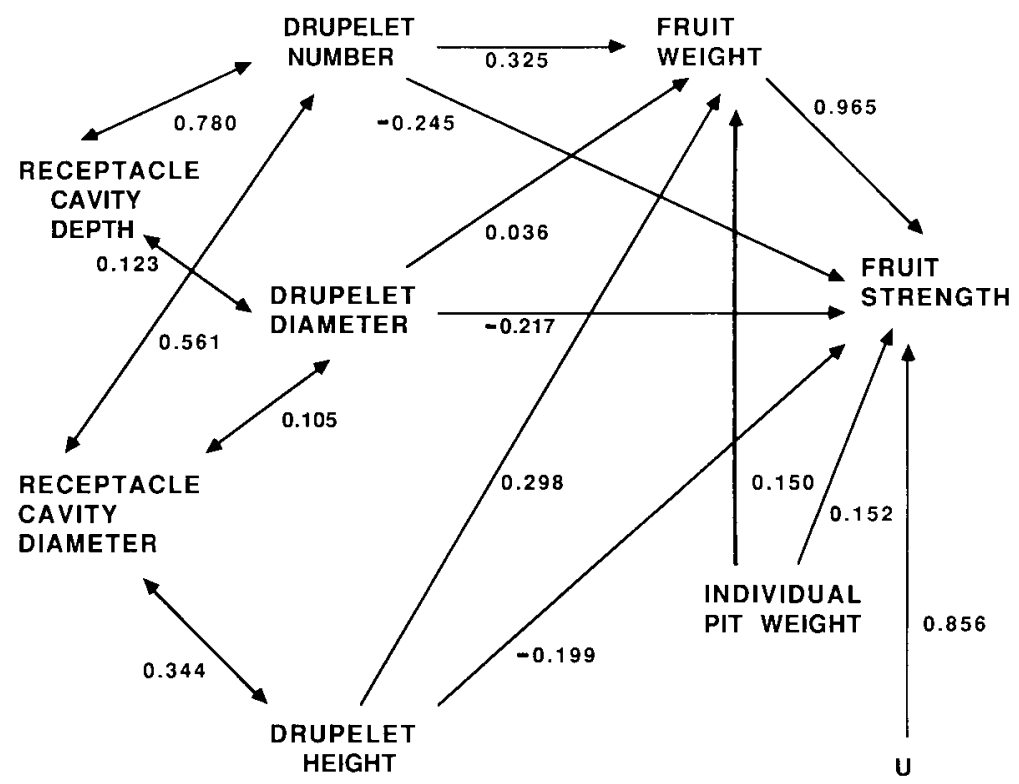

Fig. 1. Diagrammatic representation showing relationship of measured morphological characteristics to each other and fruit strength for 78 red raspberry seedlings from the cross 'Chief' $\times$ 'Chilliwack'. $\mathrm{U}=$ Contribution to total path model from unexplained variation $\mathrm{U}=\sqrt{1-R^{2}}$, with $R^{2}$ from regression analysis. 
Table 1. Mean, standard deviation, coefficient of variation, and range of fruit measurements for raspberry scedlings, $1989 .(\mathrm{n}=78)$

\begin{tabular}{|c|c|c|c|c|c|}
\hline \multirow[b]{2}{*}{$\begin{array}{l}\text { Morphological } \\
\text { characteristic }\end{array}$} & \multirow[b]{2}{*}{ Mean } & \multirow[b]{2}{*}{$\begin{array}{l}\text { Standard } \\
\text { dcviation }\end{array}$} & \multirow{2}{*}{$\begin{array}{c}\text { Coefficient } \\
\text { of } \\
\text { variation }\end{array}$} & \multicolumn{2}{|c|}{ Range } \\
\hline & & & & $\begin{array}{c}\text { Min } \\
\text { value }\end{array}$ & $\begin{array}{l}\text { Max } \\
\text { value }\end{array}$ \\
\hline \multicolumn{6}{|l|}{ Fruit } \\
\hline Strength $(\mathrm{N})$ & 1.40 & 0.36 & 0.26 & 0.65 & 2.50 \\
\hline Weight (g) & 2.58 & 0.62 & 0.24 & 1.59 & 4.39 \\
\hline \multicolumn{6}{|l|}{ Drupclet } \\
\hline Height $(\mathrm{cm})$ & 0.42 & 0.03 & 0.07 & 0.35 & 0.48 \\
\hline Diamcter $(\mathrm{cm})$ & 0.34 & 0.03 & 0.10 & 0.27 & 0.41 \\
\hline Number & 73 & 16 & 0.22 & 37 & 108 \\
\hline \multicolumn{6}{|l|}{ Receptacle cavity } \\
\hline Depth $(\mathrm{cm})$ & 0.86 & 0.14 & 0.17 & 0.55 & 1.20 \\
\hline Diamctcr $(\mathrm{cm})$ & 0.85 & 0.07 & 0.09 & 0.70 & 1.05 \\
\hline \multicolumn{6}{|l|}{ Pit weight } \\
\hline Individual (mg) & 1.56 & 0.22 & 0.14 & 1.11 & 2.24 \\
\hline
\end{tabular}

Table 2. Correlation of fruit morphological measurements with fruit weight and fruit strength for raspberry scedlings, $1989 .(n=78)$.

\begin{tabular}{|c|c|c|}
\hline \multirow{3}{*}{$\begin{array}{c}\text { Morphological } \\
\text { characteristic }\end{array}$} & \multirow{2}{*}{\multicolumn{2}{|c|}{$\begin{array}{c}\begin{array}{c}\text { Corrclation cocfficient } \\
(r)\end{array} \\
\text { Fruit }\end{array}$}} \\
\hline & & \\
\hline & Wt & Strength \\
\hline \multicolumn{3}{|l|}{ Fruit } \\
\hline Strength & $0.35^{* *}$ & -- \\
\hline Wcight & -.. & $0.35^{* *}$ \\
\hline \multicolumn{3}{|l|}{ Drupelet } \\
\hline Height & $0.55^{* *}$ & NS \\
\hline Diamcter & $0.27^{*}$ & NS \\
\hline Number & $0.66^{* *}$ & $0.24^{*}$ \\
\hline \multicolumn{3}{|l|}{ Receptacle cavity } \\
\hline Depth & $0.85^{* *}$ & $0.30^{* *}$ \\
\hline Diameter & $0.77^{* *}$ & NS \\
\hline \multicolumn{3}{|l|}{ Pit weight } \\
\hline Individual & $0.58^{* *}$ & $0.28^{* *}$ \\
\hline
\end{tabular}

the magnitude and influence of these morphological characteristics on fruit strength was possible (Fig. 1). The total of component path coefficients to fruit strength was 0.355 . Of that total, 1.310 was routed through fruit weight. All the individual components of this total were positive. The total of path coefficients routed to fruit strength, other than paths through fruit weight, was -0.955 . Each of the individual contributions to this total from morphological measurements was negative, except for pit weight, which was positive. Except for individual pit weight, increasing any morphological measurement resulted in a heavier fruit, which was a stronger fruit, but also resulted in a reduction of fruit strength directly. This reversal is possibly due to fruit becoming less structurally sound as morphological components become larger. Individual pit weight contributed to fruit strength both by providing a heavier fruit and by direct structural enhancement of fruit strength.

The contribution of each morphological characteristic to fruit strength can be calculated by the addition of the product of paths from each morphological component to fruit strength indirectly through fruit weight plus the product of paths from each morphological component to fruit strength directly. For example, the total contribution of drupelet number to fruit strength is $(0.325)(0.965)+$ $(-0.245)=0.069$. The morphological itive contribution to fruit strength was individual pit weight $(0.297)$, followed by drupelet height (0.089) and drupelet number (0.069). Receptacle cavity depth and receptacle cavity diameter provided small contributions to fruit strenght (0.031 and 0.051 , respectively). The contribution from drupelet diameter to fruit strength was large and negative $(-0.182)$ due to its very small product of path coefficients indirectly through fruit weight $(0.035)$ and a large negative coefficient directly to fruit strength $(-0.217)$. Increase in drupelet diameter resulted in a weaker fruit, as noted previously (Robbins and Moore, 1990; Robbins and Sjulin, 1989).

Drupelet height was not correlated with fruit strength (Table 2) but contributed greatly to the total of path components in path analysis (Fig. 1), indicating a causal relationship with fruit strength. Drupelet height was an important factor in fruit strength in earlier studies (Robbins and Sjulin, 1989; Robbins et al., 1988), although not within [he single genotype 'Meeker' (Robbins and Moore, 1990). Drupelet number and individual pit weight have been consistently related to and consistently contributed to fruit strength in this and earlier studies (Robbins and Moore, 1990; Robbins and Sjulin, 1989). In this work, receptacle cavity depth was correlated with fruit strength (Table 2), as it was in previous work (Robbins and Moore, 1990; Robbins and Sjulin, 1989). However, in this study, unlike the previous two, its contribution to fruit strength, as ascertained by path analysis, was small. characteristic providing the largest total pos-
This work has provided information on morphological characters that contribute to fruit strength across genotypes. Heavy red raspberry fruit having many tall drupelets that are small in diameter and contain heavy pits are most likely to have high fruit strength. Conversely, cultivars selected on the basis of fruit strength are likely to have the above fruit characteristics. This information will be of assistance in breeding firmer cultivars, since parents that provide populations high in the above characters are most likely to provide strong fruit. In selecting for firm raspberries by sight, this work suggests avoiding fruit with few, large drupelets.

The morphological model, by regression analysis, with all morphological characteristics, including fruit weight, has a low $R^{2}$ $[0.23,0.34$, and 0.59 for this study, Robbins and Moore (1990), and Robbins and Sjulin (1989), respectively]. This low $R^{2}$ resulted in a large residual (u) in the path analysis (Fig. 1). Clearly, factors other than the fruit morphological characteristics measured influence fruit strength. Some of these may include incomplete drupelet set (Daubeny et al., 1975), minor variations in fruit maturity (Sjulin and Robbins, 1987), and, possibly, weather conditions at time of harvest, water status of the fruit at time of harvest, and variations due to lateral location or fruit location on the flowering truss.

\section{Literature Cited}

Barritt, B. H., L.C. Terre, H.S. Pcpin, and H.A. Daubeny. 1980. Fruit firmness measurements in red raspberry. HortScience 15:38-39.

Daubeny, H. A., J.A. Freeman, and R. Stacc-Smith. 1975. Effects of tomato ringspot virus on drupelet set of red raspberry cultivars. Can. J. Plant Sci. 55:755-759.

Li, C.C. 1975. Path analysis-A primer. Boxwood Press, Pacific Grove, Calif.

Reeve, R. M., E. Wolford, and C.C. Nimmo. 1965. A review of fruit structure and the processing of raspberries. Food Technol. 19:78-82.

Robbins, J.A. and P.P. Moore. 1990. Fruit weight and strength in 'Meeker' red raspberry. HortScience 25:679+81.

Robbins, J.A. and T.M. Sjulin. 1989. Fruit morphology of red raspberry and its relationship to fruit strength. HortScicncc 24:776-778.

Robbins, J. A., T.M. Sjulin, and H.P. Rasmussen. 1988. Scanning electron microscope analysis of drupelet morphology of red raspberry and related Rubus genotypes. J. Amer. Soc. Hort. Sci. 113:474480.

Sjulin, T.M. and J.A. Robbins. 1984. Progress in extending raspberry shelf life-Fresh market studies of red raspberries. Proc. 74th Annu. Meeting Western Washington Hort. Assn. p. 96-98.

Sjulin, T.M. and J.A. Robbins. 1987. Effects of maturity, harvest date and storage time on postharvest quality of red raspberry fruit. J. Amer. Soc. Hort. Sci. 112:481-487. 